\title{
Зарубская Е.O.
}

Санкт-Петербургский государственный архитектурно-строительный университет E-mail:ez555@list.ru

\section{ТЕОРЕТИЧЕСКАЯ МОДЕЛЬ ЦЕНТРОВ УЛИЧНОГО СПОРТА ДЛЯ УСЛОВИЙ ХАНТЫ-МАНСИЙСКОГО АВТОНОМНОГО ОКРУГА-ЮГРЫ}

Аннотация. Современная теоретическая база уличного спорта в России требует разработки рекомендаций по проектированию архитектурных объектов в соответствии с актуальной практикой. Новые мастер-планы, основанные на единой теоретической модели сети объектов уличного спорта, позволят восполнить пропущенные типологические звенья и расиирить реализацию архитектурного и градостроительного потенциала в структуре городов. Результать исследования содержат элементы Трехуровневой модели Единой сети объектов уличного спорта для Российской Федерации и предусматривают следующие ступени для реализаџии:

- внутри страны в целлом, с грамотным распределением между регионами,

- внутри каждой отдельно взятой территории,

- внутри населенного пункта.

Особую значимость в России должно приобрести равномерное распределение объектов уличного спорта в северных регионах, где преодоление влияния экстремальных условий проживания каждым без исключения жителем является одной из ежедневных задач, которая требует соответствующих компенсаций.

Предложенная конщепция внедрения Единой системы размещуения центров уличного спорта на территории Ханты-Мансийского автономного округа - Югры содержст 3 модели для вертикального тиражирования: - от маломасштабного до крупного проекта; и 4 модели для горизонтального внедрения, представляющие собой цеентры уличного спорта:

- «ориентированные на развитие спорта высших достижений»,

- «ориентированные на развитие массового спорта»,

- «рекреационные»,

- «градообразуюшчие».

Ключевые слова: теоретическая модель, единая сеть, центр уличного спорта, Россия уличный cnopm.

Введение. Спорт в истории человечества стал первой реализованной идеей создания всемирного культа [1]. Слово «спорт» происходит от английского «disport» - забавляться, давать себе волю, шалить, развлекаться; «disport yourself》 - получать удовольствие, в особенности от физической активности [2]. «Уличный спорт» становится наилучшим воплощением концепции «чистого спорта», в котором физическая активность, нацеленная на сохранение здоровья или получение удовольствия [3], отодвигает идею соревнования на другой план и в значительной степени превращает спорт в искусство [4].

В то время как большая часть мирового населения проживает в городах и подвержена стрессу и монотонности [5], а идея Пьера де Кубертена не реализовывается в полной мере (возвышенные цели не достигаются ввиду коррупционных и допинговых скандалов [6]; вектор развития спорта от красоты и благородства честной победы, обусловленных единством духа, души и тела [7], смещается к потреблению); - в фокусе внимания на мировой спортивной сцене оказывается уличный спорт [8]. Свободный от жестких правил и поощряющий всестороннюю самореализацию, «уличный спорт» представляет собой живое взаимодействие [9] различных направлений спортивной активности с целью всестороннего освоения постоянно изменяющегося урбанизированного ландшафта [10].

Рост мирового рынка уличного спорта обусловлен и такими факторами, как появление новых направлений, развитие деловых и спортивных инноваций, рост населения среднего класса, смещение предпочтений потребителей в сторону улучшения здоровья и внешности [11]. Государственная поддержка в области здравоохранения и спорта Российской Федерации, повсеместное усложнение, многослойность, вариативность урбанизированной среды, ускорение городской жизни, наличие разнообразного оборудования и средств для катания, а также появление персонализированных программ непрерывно дополняют рост рынка [12].

Высокие инвестиционные затраты на открытие пилотных центров уличного спорта, отсутствие общероссийской концепции теоретической модели уличного спорта, неполнота нормативной документации и подходов для проектирования, малоподвижный образ жизни будет препятствовать росту рынка. Однако ожидается, что в 
ближайшее время влияние движущих факторов превзойдет влияние ограничений.

Объект исследования - теоретические модели центров уличного спорта в условиях региона Ханты-Мансийского автономного круга Югры. Цель исследования состоит в выявлении типов многофункциональных центров уличного спорта, направленных на раскрытие потенциала объектов в условиях Ханты-Мансийского автономного округа - Югры. Задача исследования заключается в рассмотрении региональной специфики размещения и проектирования объектов уличного спорта в северных регионах на примере Ханты-Мансийского автономного округа Югры.

Методология. Этап сбора эмпирических данных стартовал в октябре 2017 г. и продолжался до января 2020 г. Эмпирическая база представлена 512 опрошенными, ответы которых были дифференцированы по характеристикам пользовательского опыта: от ролевой модели до зрителя. Применен общенаучный системный подход, аналитический метод исследования, метод статистического анализа результатов проведенного автором социологического опроса. Выявление особенностей современного пользовательского опыта всех категорий городских жителей Югры с экспертным интервьюированием представителей уличного спорта позволило учесть интересы региона при проектировании архитектуры объектов уличного спорта.

Основная часть. Уличный спорт представляет собой совокупность социальных отношений и видов деятельности, организуемых внутри урбанизированного ландшафта, в том числе в специализированных учреждениях, в соответствии с потребностями основных групп спортсменов, занимающихся выбранным видом или видами уличного спорта с целью всестороннего освоения городского пространства через проведение социальных, тренировочных мероприятий и соревновательной деятельности, (где урбанизированный ландшафт - это естественный ландшафт, преобразованный человеком за счёт городской архитектуры и инфраструктуры).

Согласно интерактивным данным «Ramp Map: World Skatepark Мар» - в США (237), Великобритании (52) и Франции (27) находится сегодня более $70 \%$ совокупного количества объектов уличного спорта (452). Соотношение в мире закрытых и открытых объектов уличного спорта составляет $1: 20$. По мнению американских специалистов, Россия и Бразилия сегодня являются наиболее перспективными странами для строительства крупных закрытых объектов уличного спорта.
Несмотря на то, что темпы роста обеспеченности объектами уличного спорта в городах России значительно ниже необходимых, этнография современных российских городов предполагает массовое распространение новых типов зданий.

Уличный спорт в Российской Федерации (наша страна занимает приблизительно 1/9 часть суши [13]), должен рассматриваться, прежде всего, как единая система, - мощный актив в масштабе всего государства, отдельно взятого региона, населенного пункта, архитектурного объекта, каждый из которых представляет собой универсальную теоретическую модель для реализации, - таким образом, меры по созданию отдельных точечных объектов уличного спорта не являются исчерпывающими. Лидирующие позиции в сфере точечного развития уличного спорта сегодня занимают такие города как Москва (Street hall), Санкт-Петербург (Жесть), Красноярск (Sportex), Ярославль (Ярбатут), однако ни один из закрытых объектов не был зарегистрирован на государственном уровне в соответствии со своим прямым назначением, что подтверждает необходимость и своевременность применения системного подхода в развитии архитектуры уличного спорта.

За последние 70 лет вне архитектуры возникло более чем 50 новых направлений уличного спорта, большинство из которых связано с катанием. Восполнение пропущенных звеньев в архитектурной типологии объектов уличного спорта призвано решить проблему нехватки пространств для профессиональной подготовки и социальной защиты перспективных спортсменов.

Взаимодействие различных направлений спортивной активности, связанных с катанием, являются самыми зрелищными, востребованными и сложными в организации, поэтому, ключевой комбинацией при формировании нового типа здания, центра уличного спорта, рекомендуются скейтбординг, велосипедный спорт - BMX, скутеринг, роллер-спорт, которые в наибольшей степени отвечают всемирной концепции «постспорта», тесно связанного с процессами глобализации и внедрением в городскую среду инновационного оборудования и технологий.

Однако, если в России сегодня и появляются объекты, предусматривающие наличие в своем составе отдельных залов для занятий некоторыми направлениями уличного спорта, то единая система организации пространства в таких сооружениях продолжает демонстрировать принципы традиционной спортивной архитектуры с изолированными друг от друга функциональными блоками, - пространства для катания начинаются и заканчиваются исключительно в границах стен изолированных друг от друга выделен- 
ных залов. Конфигурации зон для катания предусматривают преимущественно ортогональную систему выстраивания траекторий движения, не поощряя обширных вариаций. В связи с отсутствием единой концепции развития уличного спорта, адаптированной к реализации в нашей стране, использование классических типологических моделей спортивных объектов в архитектуре уличного спорта в значительной степени подавляет дух свободы, первооткрывательства, взаимодействия с урбанизированной средой в уже на уровне архитектурных и градостроительных решений.

Три уровня Единой сети объектов уличного спорта:

- внутри страны в целом, с грамотным распределением между регионами,

- внутри каждой отдельно взятой территории,

- внутри населенного пункта;

с архитектурной точки зрения предполагают возможности для свободного прочтения и создания самодостаточных уникальных объектов национального масштаба с учетом местной неординарной специфики.

Первый уровень Единой сети объектов уличного спорта на территории Российской Федерации, предлагаемый исследованием, включает прежде всего северные регионы, занимающие более $70 \%$ территории всей страны. Здесь каждый из 25 млн. человек (более 17,8 \% населения России [14]), ежегодно испытывает на себе влияние экстремальных условий проживания, которые требуют соответствующих компенсаций.

Строительство центров уличного спорта в городской архитектурной среде целесообразно увязывать с государственной градостроительной политикой муниципального образования, региона и страны, - единство комплексной концепции реализации стратегии социально-экономического развития, схемы территориального планирования и бюджета на всех уровнях, - обеспечивает качественное воплощение стратегических замыслов по развитию уличного спорта в целом [15].

Рассмотрим реализацию Второго уровня Единой сети объектов уличного спорта на территории Российской Федерации на примере ХантыМансийского Автономного округа - Югры. Расчёты необходимой обеспеченности и доступности по объектам уличного спорта регионального и местного значения в соответствии с региональными нормативами градостроительного проектирования связаны с развитием планировочного каркаса. Программа размещения центров уличного спорта на территории одного региона предполагает выбор сразу нескольких городов. Предпочтение при формировании новых элементов в структуре отдается городам-лидерам, в соответствии с интенсивностью их освоения и существующими магистральными транспортными связями, с учётом природных планировочных осей и сети имеющейся спортивной инфраструктуры.

Широтное направление планировочного каркаса может быть усилено программным объединением четырех городов окружного значения, которое включает в себя автомобильный, железнодорожный и водный пути через Пермь, Ханты-Мансийск (с численностью населения 99 тыс. чел.), - Нефтеюганск (125 тыс.), - Сургут (348 тыс.), - Нижневартовск (271 тыс.), - в Томск. Ханты-Мансийск является планировочным центром первого ранга - это административный центр автономного округа, транспортно-логистический центр, центр культурного, социального, экономического развития. Сургут и Нижневартовск отнесены к планировочным центрам второго ранга. Сургут представляет собой крупный торгово-промышленный центр, административный, агломерационный центр, насыщенный экономическими, социальными функциями. Нижневартовск - промышленный, административный, агломерационный центр, расположен в восточной части автономного округа, на пути в Томскую область.

Стратегия организации сбалансированной системы объектов уличного спорта на самых ранних этапах планирования предполагает устойчивое развитие сети, состоящей из двух групп компонентов: узловых объектов уличного спорта открытых, крытых и интегрированных зданий, сооружений и комплексов, и соединительных объектов линейной или облачной инфраструктуры уличного спорта, замыкающих в непрерывную цепь все узловые элементы. Региональная специфика размещения объектов уличного спорта в северных регионах с дискомфортными природно-климатическими условиями предполагает преимущественное распространение закрытых узловых объектов (центров уличного спорта). Устойчивая модель размещения в отдельного населенного пункта должна состоять не менее чем из трех центров уличного спорта. Уровень объектов модели зависит от масштаба и значения населенного пункта, и может быть определен комбинацией:

1. Международный «Крупномасштабный проект центра уличного спорта высших достижений» (с вместимостью до 7 - 12 тыс. зрителей, этажностью от 4-х этажей);

2. Национальный «Среднемасштабный проект центра для профессионального развития уличного спорта» (до 3 тыс. зрителей, этажностью от 3-х этажей); 
3. Местный «Маломасштабный проект центра массового развития уличного спорта» (до 500 зрителей).

Инвестиционные потоки интеллектуального капитала движутся от проектов более высокого уровня вниз, - во встречном направлении, происходит возврат вложенных средств от реализации менее масштабных, более технологически проработанных и быстро окупаемых проектов [16]. Взаимный обмен интеллектуальным и финансовым капиталом обеспечивает возможность сбалансированного развития инновационной и инвестиционной деятельности при создании высокотехнологичных спортивных сооружений как в рамках отдельно взятого города, так и региона в целом [17]. Вертикальное и горизонтальное тиражирование высокотехнологичных спортивных сооружений в 4-х городах Югры, - Ханты-Мансийске, Сургуте, Нижневартовске и Нефтеюганске, - призвано реализовать синергетический потенциал новой градостроительной системы и укрепить широтное направление планировочного каркаса региона. Таким образом, первым этапом в Ханты-Мансийском Автономном округе - Югре может быть запланировано строительство до 12-ти крытых центров уличного спорта, как минимум один из которых - международного уровня.

Первый этап комплексного градостроительного развития уличного спорта в Ханты-Мансийском Автономном округе - Югре предполагает усиление прежде всего широтного направления планировочного каркаса региона в четырех городах - Ханты-Мансийске, Сургуте, Нижневартовске, Нефтеюганске. Строительство в каждом городе не менее 3-х крытых центров уличного спорта, один из которых имеет статус международного, может обеспечить выполнение сверхзадач по гармонизации и взаимоувязке спортивной деятельности региона и России в целом.

III.Общие характеристики моделей третьего, архитектурного, уровня Единой сети объектов уличного спорта внутри городов России можно объединить в 4 основных категории:

- модель первая «малые центры уличного спорта»: местное значение;

- модель вторая «средние центры уличного спорта»: районное/городское значение; многофункциональность и комплексный характер использования; структуры (в основном спортивная, рекреационная и культурно-массовая функции);

- модель третья «крупные центры уличного спорта»: городское/региональное/национальное значение; многофункциональность (соревновательные и тренировочные спортивные функции, рекреационные, культурные и иные обществен- ные функции); гибридизация спортивной и зрительной функций, принципиальная гибкость и сценарность пространства, экологичность/peсурсо- и энергосбережение;

- модель четвертая «крупнейшие центры уличного спорта»: международное значение; гибридизация всех функций с целью воспроизведения атмосферы аутентичного городского и природного пространства, слияние урбанизированной, культурной и спортивной среды, сценарность, принципиальная гибкость, адаптируемость к новым потребностям; полифункциональность; экологичность/ресурсо- и энергосбережение.

Инициация формирования третьего уровня Единой сети объектов уличного спорта на территории Российской Федерации в качестве составной части структурных элементов населенных мест, от самых начальных ступеней до крупнейших общегородских и загородных объектов, в том числе Олимпийских комплексов предлагает и создание новой Классификации универсальных центров уличного спорта по основному назначению, которая включает:

- «ориентированные на развитие спорта высших достижений» с 75-90 \% пространств спортивного назначения,

- «ориентированные на развитие массового спорта» с 70-85 \% пространств спортивного назначения,

- «рекреационные» с 60-75\% пространств спортивного назначения,

- «градообразующие» с 50-65 \% пространств спортивного назначения.

Центр уличного спорта в северных городах представляет собой интегрированный в городскую среду интеллектуальный архитектурный объект нового типа с крытой спортивной зоной, объединяющей воздушное пространство, архитектуру и ландшафт, с целью круглогодичного освоения через возможность занятий широким диапазоном новых дисциплин. Планировочная структура предусматривает слияние в одном объекте уличного спорта типологических моделей театра и стадиона. Модели, «ориентированные на развитие спорта высших достижений» и «ориентированные на развитие массового спорта», типологически тяготеют в большей степени к схеме стадиона, модели «рекреационные» и «градообразующие» - проявляют в большей степени типологию театров. Для всех 4-х предложенных вариантов универсальных центров уличного спорта характерны закольцованность, единство всех внешних и внутренних спортивных маршрутов, сценарность пространств, интенсификация функций. Функциональная схема представленного исследованием нового типа здания - центра уличного спорта, содержит в себе две группы единых, 
взаимоувязанных между собой спортивных пространств для различных дисциплин уличного спорта, сопровождаемых на всех этапах зрительными зонами. В архитектурном отношении закрытые объекты уличного спорта демонстрируют укрупнение масштаба открытой архитектуры, превращение интровертного градостроительного плана в экстравертный.

Развитие спортивного потенциала ХантыМансийского автономного округа - Югры в соответствии с мировыми трендами и национальными ценностями позволит усилить способность к физической и психологической адаптации общества и создать лучшие условия для реализации отдельно взятой личности.

Выводы. Все в мире говорит о будущем перерождении спорта. Связь различных направлений через молниеносное изобретение, трансформацию, непрерывное слияние, разветвление, наложение концепций существующих спортивных дисциплин и взаимосвязанность этих изменений с усложнением городского креативного пространства уже нельзя игнорировать. Новейший виток эволюции объектов уличного спорта находится в режиме постоянной трансформации.

Глобальная концепция уличного спорта уже включает в себя более 65-ти выявленных в исследовании видов и дисциплин уличного спорта, а также направлений активного досуга, связанных преимущественно с катанием, однако система строительства единой инфраструктуры уличного спорта в мастер-планы развития городов до настоящего времени на территории Российской Федерации не была разработана.

Общая концепция распространения уличного спорта основывается на создании единой сети, комбинирующей две группы объектов - узловых (центров уличного спорта) и соединительных, которые подразделяются, в свою очередь, на линейные (трассы для однонаправленного движения) и облачные (пространства для катания с перемещениями в различных направлениях), представляя собой единую городскую спортивную сцену.

Результать исследования содержат Трехуровневую модель Единой сети объектов уличного спорта для Российской Федерации и предусматривают следующие ступени для реализациии:

- внутри страны в целом, с грамотным распределением между регионами,

- внутри каждой отдельно взятой территории,

- внутри населенного пункта.

По итогам 2018 года доля населения, систематически занимающихся физической культурой и спортом составила 39,8 \% (54,2 млн. человек)
[19], - 8 \% от общей численности населения регулярно занимается нетрадиционными, в том числе уличными, видами спорта. Особую значимость в России должно приобрести равномерное распределение объектов уличного спорта по северным регионам, где преодоление влияния экстремальных условий проживания на каждого жителя является одной из ежедневных задач и требует соответствующих компенсаций. Расширение доступности объектов уличного спорта среди всех возрастов и социальных групп населения, «не оставляя никого», лежит в основе повестки дня в области справедливости [20]. Наиболее предпочтительным для северных регионов с дискомфортными природно-климатическими условиями является распространение закрытых компактных узловых объектов.

Основные группы характеристик новой типологии зданий - центров уличного спорта, можно объединить в 4-х теоретических моделях, в соответствии с масштабом объекта:

- модель первая «малые центры уличного спорта»,

- модель вторая «средние центры уличного спорта»,

- модель третья «крупные центры уличного спорта»,

- модель четвертая «крупнейшие центры уличного спорта».

Предложенная в исследовании концепция пилотного внедрения Единой системы размещчения центров уличного спорта на территории Ханть-Мансийского автономного округа Югры содержит первые 3 модели для вертикального тиражирования: - от маломасштабного до крупного проекта; и 4 модели для горизонтального внедрения, представляющие собой центры уличного спорта:

- «ориентированные на развитие спорта высших достижений»,

- «ориентированные на развитие массового спорта»,

- «рекреационные»,

- «градообразующие».

Динамично развивающиеся города мира в архитектуре центров уличного спорта находят колоссальный ресурс и возможности для преобразования городской среды [18]. Включение строительства единой инфраструктуры уличного спорта в мастер-планы развития городов предоставляет возможности к созданию новых интеллектуальных архитектурных объектов для долгосрочных инвестиций с целью всестороннего оздоровления населения и комплексного повышения качества городской среды. 


\section{БИБЛИОГРАФИЧЕСКИЙ СПИСОК}

1. The visionary founder of the modern Olympic Games. Lausanne: International Olympic Committee. 2020. [Электронный ресурс]. Систем. требования: Safari. URL: http://www.olympic.org/pierre-de-coubertin. (дата обращения: 03.02.2020).

2. Disport. Cambrige Dictionary: Cambrige University Press. 2020. [Электронный ресурс]. Систем. требования: Safari. URL: http://www.dictionary.cambrige.org/ru/словарь/англо-русский/disport?q=Disport. (дата обращения: 03.02.2020).

3. Sport. Cambrige Dictionary: Cambrige University Press. [Электронный ресурс]. Систем. требования: Safari. URL: http://www.dictionary.cambrige.org/ru/словарь/англо-

pyсский/sport_1?q=Sport. (дата обращения: 03.02.2020).

4. Зарубская Е.О. «Уличный спорт» как специфический объект проектирования // Системные технологии. 2018. № 28. С. 108-112.

5. World Population Prospects 2019 - Highlights. United Nations. 2019. [Электронный peсурс]. Систем. требования: AdobeAcrobatReader. URL: http://www.population.un.org/wpp/Publications/Files/WPP2019_Highlights.pdf. (дата обращения: 03.02.2020).

6. Kayzer B. Ethical Aspects of Doping and Anti-Doping. Thesis of Swansea University. 2018. [Электронный ресурс]. Систем. требования: AdobeAcrobatReader. URL: http://www.serval.unil.ch/resource/sev-

ral:BIB_B9C6372028C7.P001/REF. (date of treatment: 03.02 .2020 ).

7. Reardon CL., Hainline B., Miller Aron C., Baron D. Mental health in elite athletes: International Olympic Committee consensus statement // British Journal of Sports Medicine. 2019. № 5. Pp. 667-699.

8. Zarubskaya E.O. Street sports center as a new type of public building // Themed collection of papers from international conferences by Scieuro. Scieuro. 2018. March. Pp. 26-30.

9. Zarubskaya E.O. The genesis of the social and cultural changes in the street sports architecture // Themed collection of papers from international conferences by HNRI «National development». HNRI "National development". 2018. December. C. 143-145.

10.Зарубская Е.О. Современные тенденции развития типологии центров уличного спорта. Вестник Евразийской науки. 2018. № 3. [Электронный ресурс]. Систем. требования: AdobeAcrobatReader. URL: https://esj.today/PDF/57SAVN318.pdf. (дата обращения: 03.02.2020).

11.Fitness and Recreational Sports Centers Market by Type and Age Group - global Opportunity
Analysis \& Industry Forecast, 2017-2023. ResearchAndMarkets.com. 2018. [Электронный peсурс]. Систем. требования: Safari. URL: http://www.researchandmarkets.com/research/2nz3t 1/global_fitness? $\mathrm{w}=4$ (дата обращения: 03.02.2020).

12.Fitness and Recreational Sports Centers Market by Type and Age Group - global Opportunity Analysis \& Industry Forecast, 2017-2023. ResearchAndMarkets.com. 2018. [Электронный peсурс]. Систем. требования: Safari. URL: http://www.researchandmarkets.com/research/2nz3t 1/global_fitness? $\mathrm{w}=4$ (дата обращения: 03.02.2020).

13.Россия в цифрах. Федеральная служба государственной статистики. 2018. [Электронный ресурс]. Систем. требования: Safari. URL: http://www.gks.ru/free_doc/doc_2018/rusfig/rus18. pdf (дата обращения: 03.02.2020).

14.Россия в цифрах. Федеральная служба государственной статистики. 2018. [Электронный ресурс]. Систем. требования: Safari. URL: http://www.gks.ru/free_doc/doc_2018/rusfig/rus18. pdf (дата обращения: $03.02 .20 \overline{2} 0$ ).

15.Расширенное заседание президиума Госсовета по вопросам улучшения жилищных условий населения и формирования благоприятной городской среды. Президент России. 2019. [Электронный ресурс]. Систем. требования: Safari. URL:

http://www.kremlin.ru/events/president/news/59817 (дата обращения: 03.02.2020).

16.Фомкин С.В. Формирование структурнопараметрической модели сбалансированного развития инновационной и инвестиционной деятельности при производстве и строительстве высокотехнологичных спортивных сооружений // Transport business in Russia. 2012. № 6. C. 9-12.

17.Фомкин С.В. Формирование структурнопараметрической модели сбалансированного развития инновационной и инвестиционной деятельности при производстве и строительстве высокотехнологичных спортивных сооружений // Transport business in Russia. 2012. № 6. C. 9-12.

18.Glenney B., Mull S. Skateboarding and the Ecology of Urban space. Journal of sport and social issues. 2018. [Электронный ресурс]. Систем. требования: Safari. URL: http://www.ncbi.nlm.nih.gov/articles/PMC6269152 (дата обращения: 03.02.2020).

19.Доклад о роли субъектов Российской Федерации и муниципальных образований в развитии физической культуры, спорта и туризма. Министерство спорта Российской Федерации. 2019. [Электронный ресурс]. Систем. требования: MicrosoftWord. URL: http://www.minsport.gov.ru/2019/doc/Doklad.docx (дата обращения: 03.02.2020). 
20.Accessibility and Development. Mainstreaming disability in the post-2015 development agenda. United Nations. 2018. [Электронный ресурс]. Систем. требования:
AdobeAcrobatReader.

URL: http://www.un.org/disabilities/documents/accessibil ity_and_development.pdf (дата обращения: 03.02.2020).

Информачия об авторах

Зарубская Елена Олеговна, аспирант. E-mail: ez555@list.ru. Санкт-Петербургский государственный архитектурно-строительный университет. Россия, 190005, Санкт-Петербург, ул. 2-я Красноармейская, д.4.

Поступила в мае 2019 г.

(C) Зарубская Е.O., 2020

Zarubskaya E.O.

Saint Petersburg State University of Architecture and Civil Engineering, E-mail:ez555@list.ru

\section{THEORETICAL MODEL OF STREET SPORT OBJECTS IN KHANTY-MANSI AUTONOMOUS OKRUG-YUGRA}

Abstract. The modern theoretical basis of street sports in Russia requires the working out of recommendations for the design of architectural objects in accordance with the relevant practice. New masterplans based on the theoretical model of the unified network of street sports objects will allow to fill the missing typological links and to expand the use of architectural and town-planning potential of the cities. The results of research contain the elements of a three-level model of street sports objects for Russian Federation and provide the following steps of implementation:

- inside the country with competent distribution by regions,

- inside of each separately considered area,

- inside of each settlement.

The special importance in Russia should take the uniform distribution of street sports centers between the northern regions, where overcoming the influence of extreme living conditions by each and every resident is one of the daily tasks and requires appropriate compensations.

The proposed conception for the introduction of a unified system for the placement of street sports centers in the region contains 3 models for vertical replication (from small to large project) and 4 models for horizontal implementation of street sports objects:

- «focused on big sports development»,

- «focused on mass sports development»,

- «recreational»,

- «city-forming».

Keywords: theoretical model, net, street sports center, Russia, street sports.

\section{REFERENCES}

1. The visionary founder of the modern Olympic Games. Lausanne: International Olympic Committee. Safari. URL: http://www.olympic.org/pierrede-coubertin. (date of treatment: 03.02.2020).

2. Disport. Cambrige Dictionary: Cambrige University Press. Safari. URL: http://www.dictionary.cambrige.org/ru/словарь/англо-русский/disport? $\mathrm{q}=$ Disport. (date of treatment: 03.02.2020).

3. Sport. Cambrige Dictionary: Cambrige University Press. Safari. URL: http://www.dictionary.cambrige.org/ru/словарь/англо-

русский/sport_1?q=Sport. (date of treatment: 03.02.2020).

4. Zarubskaya E. «Street Sports» as a Specific Object of Architectural Design». [Ulichnij sport kak specificheskij ob"ekt arhitecturnogo proektirovaniya] System technologies. 2018. No. 28. Pp. 108112. (rus)
5. World Population Prospects 2019 - Highlights. United Nations. 2019. AdobeAcrobatReader. URL: http://www.population.un.org/wpp/Publications/Files/WPP2019_Highlights.pdf. (date of treatment: 03.02.2020).

6. Kayzer B. Ethical Aspects of Doping and Anti-Doping. Thesis of Swansea University. 2018. AdobeAcrobatReader. URL: http://www.serval.unil.ch/resource/sev-

ral:BIB B9C6372028C7.P001/REF. (date of treatment: 03.02.2020).

7. Reardon C.L., Hainline B., Miller Aron C., Baron D. Mental health in elite athletes: International Olympic Committee consensus statement. British Journal of Sports Medicine. 2019. № 5. Pp. 667-699.

8. Zarubskaya E. Street sports center as a new tpe of public building. Themed collection of papers 
from international conferences by Scieuro. Scieuro. 2018. March. Pp. 26-30.

9. Zarubskaya. E. The genesis of the social and cultural changes in the street sports architecture. Themed collection of papers from international conferences by HNRI National development. HNRI "National development". 2018. December. Pp. 143145. (rus)

10.Zarubskaya E. The modern trends in the development of typology and system of street sports intitutions. The Eurasian Scientific Journal. [Sovremennye tendencii razvitiya tipologii centrov ulichnogo sporta] 2018. № 3. AdobeAcrobatReader. URL: https://esj.today/PDF/57SAVN318.pdf. (date of treatment: 03.02.2020). (rus)

11.Fitness and recreational sports centers market by type and age group - global opportunity analysis and industry forecast, 2017-2023. ResearchAndMarkets.com. 2018. Safari. URL: http://www.researchandmarkets.com/re-

search $/ 2 \mathrm{nz} 3 \mathrm{tl} / \mathrm{global}$ fitness? $\mathrm{w}=4$. (date of treatment: 03.02.2020).

12. Fitness and recreational sports centers market by type and age group - global opportunity analysis and industry forecast, 2017-2023. ResearchAndMarkets.com. 2018. Safari. URL: http://www.researchandmarkets.com/re-

search $/ 2 \mathrm{nz} 3 \mathrm{tl} / \mathrm{global}$ fitness? $\mathrm{w}=4$. (date of treatment: 03.02.2020).

13. Russia in numbers. [Rossiya $\mathrm{v}$ cifrah] Federal State Statistics service. 2018. AdobeAcrobatReader. URL: http://www.gks.ru/ free_doc/doc_2018/rusfig/rus18.pdf. (date of treatment: 03.02.2020). (rus)

14. Russia in numbers. [Rossiya v cifrah] Federal State Statistics service. 2018. AdobeAcrobatReader. URL: http://www.gks.ru/ free_doc/doc_2018/rusfig/rus18.pdf. (date of treatment: 03.02.2020). (rus)

15. Enlarged meeting of the state counsil presidium on improving housing conditions and creating a favorable urban environment. [Rasshirennoe zasedanie prezidiuma Gossoveta po voprosam uluchsheniya zhilishchnyh uslovij naseleniya $\mathrm{i}$ formirovaniya blagopriyatnoj gorodskoj sredy] President of Russia. Innopolis. 2019. Safari. URL: http://www.kremlin.ru/events/presi-

dent/news/59817. (date of treatment: 03.02.2020). (rus)

16. Fomkin S. Formation of structural-parametric model for the balanced development of innovative and investment activities in the production of high tech sport facilities. [Formirovanie strukturnoparametricheskoj modeli sbalansirovannogo razvitiya innovacionnoj deyatelnosti pri proizvodstve i stroitel'stve vysokotekhnologichnyh sportivnyh sooruzhenij] Transport business in Russia. № 6. 2012. Pp. 9-12. (rus)

17.Fomkin S. Formation of structural-parametric model for the balanced development of innovative and investment activities in the production of high tech sport facilities. [Formirovanie strukturnoparametricheskoj modeli sbalansirovannogo razvitiya innovacionnoj deyatelnosti pri proizvodstve i stroitel'stve vysokotekhnologichnyh sportivnyh sooruzhenij] Transport business in Russia. № 6. 2012. Pp. 9-12. (rus)

18. Glenney B., Mull S. Skateboarding and the Ecology of Urban space. Journal of sport and social issues. 2018. AdobeAcrobatReader. URL: http://www.ncbi.nlm.nih.gov/articles/PMC6269152. (date of treatment: 03.02.2020).

19. Report on the role of regions of Russian Federation and municipalities in the development of physical education, sports and tourism. [Doklad o roli sub"ektov Rossijskoj Federacii I municipal'nyh obrazovanij v razvitii fizicheskoj kul'tury, sporta i turizma] Ministry of sports of Russian Federation. 2019. MicrosoftWord. URL: http://www.minsport.gov.ru/2019/doc/Doklad.docx. (date of treatment: 03.02.2020). (rus)

20.Accessibility and development. Mainstreaming disability in the post-2015 development agenda. United Nations. 2018. AdobeAcrobatReader. URL: http://www.un.org/disabilities/documents/accessibility_and_development.pdf. (date of treatment: 03.02.2020).

Information about the authors

Zarubskaya, Elena O. Postgraduate student. E-mail: ez555@list.ru. Saint Petersburg State University of Architecture and Civil Engineering. Russia, 190005, Saint Petersburg, 2nd Krasnnoarmeyskaya St., 4.

\section{Received in May 2019}

\section{Для цитирования:}

Зарубская Е.О. Теоретическая модель центров уличного спорта для условий Ханты-Мансийского автономного округа -Югры // Вестник БГТУ им. В.Г. Шухова. 2020. № 3. С. 89-96. DOI: 10.34031/20717318-2020-5-3-89-96

\section{For citation:}

Zarubskaya E.O. Theoretical model of street sport objects in Khanty-Mansi autonomous okrug-Yugra. Bulletin of BSTU named after V.G. Shukhov. 2020. No. 3. Pp. 89-96. DOI: 10.34031/2071-7318-2020-5-3-89-96 